\title{
MANAGEMENT OF URINARY TRACT INFECTIONS
}

\author{
Magda PANAITESCU ${ }^{1}$, Daniela Maria ȘANDRU ${ }^{2}$ \\ ${ }^{1}$ Universidad "Latina” de Panama, Rep. de Panama, mpanaitescu@ulatina.edu.pa \\ 2 "Lucian Blaga” University of Sibiu, Romania, daniela.sandru@ulbsibiu.ro
}

\begin{abstract}
Urinary tract infection (UTI) is one of the most common pathological conditions. The positive prediction for UTI of clinical symptoms oscillates around 0.5 even lower in the case of urethral syndrome in women. An appreciable number of UTIs evolve asymptomatically, and the child under the age of 2 years the symptoms of UTI are nonspecific.

The total number of germs in the urine is determined and expressed in UCF / $\mathrm{ml}$. No colonies appeared after 18-24 hours of incubation, so the negative result was released $(<1000 \mathrm{UCF} / \mathrm{ml}$ or $<103 \mathrm{CFU} / \mathrm{ml})$.
\end{abstract}

KEYWORDS: urinary infections, germs, microbiological examination, antibiotics.

\section{INTRODUCTION}

The identification of the etiological agent, its testing with antibiotics have an essential role in establishing the treatment scheme (Moldovan et al., 2005). The largest number of samples that clutter the clinical laboratory are those of urine, (Mumtaz et al., 2008; Hanna-Wakim et al, 2015; Grabe et al, 2016) whose microbiological examination requires a certain discernment not to deplete laboratory resources in investigations without purpose or even with erroneous results, harmful to the patient. (Licker et al., 2019). Modern knowledge of microbiology and immunology in the field of urinary tract infection has seen considerable progress, which has completely changed the conception of the pathogenesis of urinary tract infection. (Grigoraş et al, 2002; Verhelst et al., 2005; Hooton, 2012; Foxman, 2014). Studies in the field have concluded that E coli, S. saprophyticus, Enterococcus spp., K. pneumoniae P. mirabilis are microorganisms that produce uncomplicated UTI infections, but antibiotic-resistant E. coli, P. aeruginosa, Acinetobacter baumannii, Enterococcus spp., Staphylococcus spp., produce complicated UTI infections. Frequently encountered in case of catheter-associated urinary tract infection are P. mirabilis, Morganella morganii, Providencia stuartii, C. urealyticum, Candida spp., and of recurrent UTI are P. mirabilis, K. pneumoniae, Enterobacter spp. antibiotic-resistant E. coli, Enterococcus spp., Staphylococcus spp. (Sobel et al. 2014). The treatments applied can be with antibiotics or using plants with antibacterial potential (Lengyel et al. 2019). Treatments based on silver nanoparticles can also be used (Lengyel et al. 2019).

Isolated lymphocytes can migrate among epithelial cells; together with leukocytes eliminated by the kidneys, they normally do not exceed 400000 cells / hour (Jehl et al, 2004; Foxman, 2002; Dason et al, 2011).

Quantitative urine culture allows to determine the number of germs in the urine. $0.001 \mathrm{ml}(\mu \mathrm{l})$ of urine is inoculated onto appropriate culture media. After an aerobic incubation, overnight the colonies formed are counted and multiplied by 1000 (no. Colonies X 1000), resulting in the number of germs in the urine (Nicolle et al, 2005; Kodner et al, 2010; Bahadin et al, 2011; Nielubowicz, 2010).

Cultivated germs are identified based on morpho-dye, culture and biochemical characteristics. If conventional methods are not sufficient to identify the germ, automatic identification is used using the Vitek2 Compact system based on the colorimetric method.

Susceptibility testing is performed by the diffusimetric or automatic method (Vitek 2 Compact - turbidimetric principle).

\section{MATERIALS AND METHODS}

- Vitek 2 Compact automatic analyzer. Vitek2 Compact identification cards / antibiogram;

- medium Blood agar, CLED agar, Mueller Hinton, Simmons, MIU, Levine, solid Chapman

- $\quad$ antibiotic discs

- physiological serum

- complex biochemical tests (API identification kits), agglutination tests (for Staphylococcus spp., Streptococcus spp.)

- reference strains (E coli, S. saprophyticus, Enterococcus spp., K. pneumoniae P. mirabilis, P. aeruginosa, Acinetobacter baumannii, Enterococcus spp., Staphylococcus spp.).

The necessary media (blood agar, CLED) for cultivation will be prepared according to the prospectus for the preparation of culture media. The culture media and materials are brought to room temperature.

Sowing procedure:

urine samples are inoculated within a maximum of half an hour of receipt; initially the urine is shaken manually; the calibrated loop of $0.001 \mathrm{ml}$ of urine is inserted perpendicularly, which corresponds to $1 \mu \mathrm{l}$; unload the loop on blood agar and spread on the CLED identically (half plate)

incubate aerobically at $37^{\circ}$ for 18-24 hours; if a mycological examination is required, it is also seeded on a Sabouraud medium plate with chloramphenicol and incubated for 3 days at $25^{\circ} \mathrm{C}$;

if sowing takes place in an emergency, after $4 \mathrm{pm}$, the plates are kept in the thermostat at incubation for at least 18 hours.

The results of the analysis can be influenced by the following factors: Urine being a good culture medium, after harvesting the 
bacteria continue to multiply, multiplication of bacteria in collected urine; over $90 \%$ of UTIs are monobacillary infections. Detection of two types of germs often requires repeated urine culture to confirm the involvement of both germs. Simultaneous detection of 3 or more types of germs in the urine emitted spontaneously always means contamination of the sample and urine culture is uninterpretable or infections with undetectable microorganisms by urine culture.

\section{RESULTS AND DISCUSSIONS}

Quantitative urine culture seems to be the most convenient and accurate test for a bacteriuria.

The plates are examined after an appropriate incubation period. If colonies do not appear after 18-24 hours of incubation, the negative result is released $(<1000 \mathrm{UCF} / \mathrm{ml}$ or $<103 \mathrm{CFU} / \mathrm{ml}$ ).

If colonies appear: count the colonies and multiply by 1000 (because we use a $0.001 \mathrm{ml}$ or $1 \mu \mathrm{l}$ loop for sowing). Thus, if there are 40 colonies on the plate, the number of germs will be $40,000 \mathrm{CFU} / \mathrm{ml}$. Further processing is performed according to tables 1,2 .

Table 1. Criteria for processing primary cultures obtained from urine collected from medium jet or permanent catheter

\begin{tabular}{|l|l|l|}
\hline Possible germs & No. of colonies & Processing \\
\hline Staphylococcus spp & $>40$ & ID, TSA / AST \\
\hline Candida albicans & $>10$ & ID, TSA / AST \\
\hline Enterobacteriaceae & $>110$ & ID, TSA / AST \\
\hline$P$. aeruginosa & $>10$ & ID, TSA / AST \\
\hline Acinetobacter baumannii & $>10$ & ID, TSA / AST \\
\hline Klepsiella pneumoniae & $>10$ & ID, TSA / AST \\
\hline
\end{tabular}

Table 2. Identification of isolates.

\begin{tabular}{|l|l|}
\hline Characteristic colonies for: & Biochemical identification tests \\
\hline lactose-positive enterobacteria & Simmons, urease, indole production \\
\hline lactose-negative enterobacteria & Simmons, urease, indole production, mobility, oxidase \\
\hline
\end{tabular}

Biological reference range:

- lower detection limit $103 \mathrm{CFU} / \mathrm{ml}$;

- there is no absolute significance threshold for the diagnosis of UTI.

- Reportable range of examination results

- the results are expressed in CFU / $\mathrm{ml}$ (count the colonies developed and multiply by 1000).

- Negative result: <1000 CFU / ml or $103 \mathrm{CFU} / \mathrm{ml}$ or $<103 \mathrm{CFU} / \mathrm{ml}$

- Nr. of germs below the significant: insignificant growth.

\section{CONCLUSIONS}

If the doctor requests simultaneous uroculture and urine biochemical examination, the laboratory doctor may make additional comments to clarify the results obtained in which no other clinical data are available:

Significant leukocyturia at the clinical examination of negative urine / urine culture: "Patient under antibiotic treatment or urogenital disease?"; normal biochemical examination + uroculture with> $105 \mathrm{CFU} / \mathrm{ml}$ : "Possible onset of urinary tract infection or incorrectly preserved urine"; significant
- $\quad$ Mixed crops (> 3 tpg): insignificant growth (> 3 types of germs); In case of leukocyturia or typical symptomatology, repetition of uroculture is required.

The preliminary result describe the morphology of the isolated germ / name of the germ, CFU / $\mathrm{ml}$ and mention: antibiogram and / or identification in progress.

The antibiogram is obtained by culturing the tested germ, in vitro, under standard conditions, in the presence of decreasing amounts of antibiotic. The antibiotics used for the test are chosen depending on the natural spectrum of activity of the tested bacterium and the location of the infectious outbreak.

The final result describe the name of the germ CFU / ml, TSA / AST.

leukocyturia at the biochemical examination of urine + urine culture with $<105 \mathrm{CFU} / \mathrm{ml}$ : "Patient under antibiotic treatment? Was the sample collected correctly?".

The most common germs in the etiology of ITU are:

Gram (-) glucose-fermentative bacills (Escherichia coli, Klebsiella, Enterobacter, Proteus)

Gram (-) glucose-nonfermentative bacills (Acinetobacter, Pseudomonas)

Gram (+) cocci (Enterococcus ssp., Staphylococcus aureus) 
Candida albicans causes urethrocystitis in diabetic patients.

\section{REFERENCES}

1. Bahadin J, Teo SS, Mathew S., Aetiology of communityacquired urinary tract infection and antimicrobial susceptibility patterns of uropathogens isolated. Singapore Med J., Vol. 52, pp. 415-420, (2011).

2. Foxman B. Epidemiology of urinary tract infections: incidence, morbidity, and economic costs. Am J Med, Vol. 113, pp. 5-13, (2002).

3. Foxman B. Urinary tract infection syndromes: occurrence, recurrence, bacteriology, risk factors, and disease burden. Infect Dis Clin North Am, Vol. 28, pp. 1-13, (2014).

4. Grabe M, Bjerklund-Johansen TE, Botto H, European Association of Urology. Guidelines on urological infections. Available at: http://uroweb.org/wpcontent/uploads/19-Urological-infections_LR2.pdf, (2015).

5. Grigoraş D., Vasile L., Principii de screening şi studiul infecţiei cu Papilloma virus uman în cancerul de col uterin, Ed. Eurobit, Timişoara, (2002).

6. Hanna-Wakim RH, Ghanem ST, El Helou MW,. Epidemiology and characteristics of urinary tract infections in children and adolescents. Front Cell Infect Microbiol, Vol. 5, No.45, (2015).

7. Health Promotion Board Singapore. Urinary tract infection. Available at: http://www.healthhub.sg/a-z/diseases-andconditions/210/urinarytractinfection, (2016).

8. Hooton TM., Uncomplicated urinary tract infection. New Engl J Med., Vol. 366, pp. 1028-1037, (2012).

9. Jehl F., Chomarat M., Weber M., Gerard A., De la antibiogramă la prescripţie, Ed. Ştiinţelor Medicale, Bucureşti, (2004).

10. Kodner CM, Thomas Gupton EK, Recurrent urinary tract infections in women:diagnosis and management. Am Fam Physician, Vol. 82, pp. 638-643, (2010).

11. Lengyel E. and Panaitescu M,. Chemical compounds from thymus vulgaris and their antimicrobial activity, Management of Sustainable Development, Sibiu, Romania, Vol. 11, No.1, pp. 25-28, (2019).

12. Lengyel E., Panaitescu M., Frum A., The action of silver nanoparticles on bacterial strains, Scientific Study \& Research, Chemistry \& Chemical Engineering, Biotechnology, Food Industry, Vol. 20, No.3, pp. 481 - 486, (2019).

13. Ministry of Health Singapore. Costs and financing: kidney\&urinary tract infections. Dason S, Dason JT, Kapoor A. Guidelines for the diagnosis and management of recurrent urinary tract infection in women. Can Urol Assoc J., Vol. 5, pp. 316-322, (2011).

14. Moldovan R., Curs de microbiologie medical, vol. II, lito UMFT, (2005).

15. Mumtaz Shamim, Mumtaz Ahmad, Irum Aftab, Naeem Akhtar, Masood ul Hassan, Abdul Hamid - Aerobic vaginal pathogens and their sensitivity pattern. J Ayub Med Coll Abbottabad, Vol. 20, No.1, pp. 113- 117, (2008).

16. Nicolle LE, Bradley S, Colgan R, et al., Infectious Diseases Society of America;American Society of Nephrology;American Geriatric Society. Infectious Diseases Society of America guidelines for the diagnosis and treatment of asymptomatic bacteriuria in adults. Clin Infect Dis., Vol. 40, pp. 643-654, (2005).

17. Nielubowicz GR, Mobley HL., Host-pathogen interactions in urinary tract infection. Nature Rev Urol., Vol. 7, pp. 430441. This review compares the strategies used by two important uropathogens, E. coli and P. mirabilis, the host response to each pathogen, and the current treatments and therapies to prevent UTIs, (2010).

18. Sobel JD, Kaye D., Urinary tract infections. In: Mandell GL, Bennett JE, eds. Principles and Practice of Infectious Diseases, 8th ed. Philadelphia: Elsevier Saunders,pp. 886913, (2014).

19. Verhelst R., H., Verstraelen G., Claeys G., Verschraegen L., Van Simaey C., De Ganck E., De Backer M., Temmerman and M. Vaneechoutte., Comparison between Gram stain and culture for the characterization of vaginal microflora: Definition of a distinct grade that resembles grade I microflora and revised categorization of grade I microflora. BMC Microbiol., pp. 5:61, (2005). 